\title{
BREVES NOTAS BIOGRÁFICAS SOBRE ALFREDO PEDRO GUISADO
}

\author{
BRIEF BIBLIOGRAPHY NOTES ABOUT ALFREDO \\ PEDRO GUISADO
}

Francisco de Barros e Vasconcellos Guisado"

Resumo: Este depoimento apresenta aspectos biográficos de Alfredo Pedro Guisado (1891-1975), sua participação em importantes revistas literárias, e os livros de sua autoria, sua atuação na vida cultural portuguesa e galega e também a relação com os companheiros da revista Orpheu.

Palavras-chave: Alfredo Guisado; Exílio; Galiza

ABstRACT: This statement presents biographical aspects of Alfredo Pedro Guisado (1891-1975), his participation in major literary magazines, his poems and essays, his performance in the Portuguese and Galician cultural life and also the relationship with fellows of Orpheu magazine.

KeYwords: Alfredo Guisado; Exílio; Galiza

"Pesquisador Independente - Portugal sobrinho-bisneto de Alfredo Guisado. Email: fmcmbv@gmail.com 
Alfredo Pedro Guisado nasceu em Lisboa a 31 de Outubro de 1891, em pleno Rossio, no número 108, edíficio que pertencia a seus pais, António Venâncio Guisado y Toucedo e Benita Abriz Gonzalez, proprietários do famoso restaurante Irmãos Unidos, sito no mesmo edifício (onde actualmente se situa a camisaria Moderna).

De ascendência Galega, sendo os pais naturais da paróquia de Pias (concelho de Ponteareas, Pontevedra), a família já estava vinculada à capital Lusa desde há duas gerações, pois o seu avô materno - Florêncio Abril Bugarin - e o seu tio avô-António José Abril Bugarin - foram os fundadores do restaurante já referenciado e que era conhecido pelos membros do Orpheu como o "matafomes", pois sabiam que naquele establecimento nada lhes era negado.

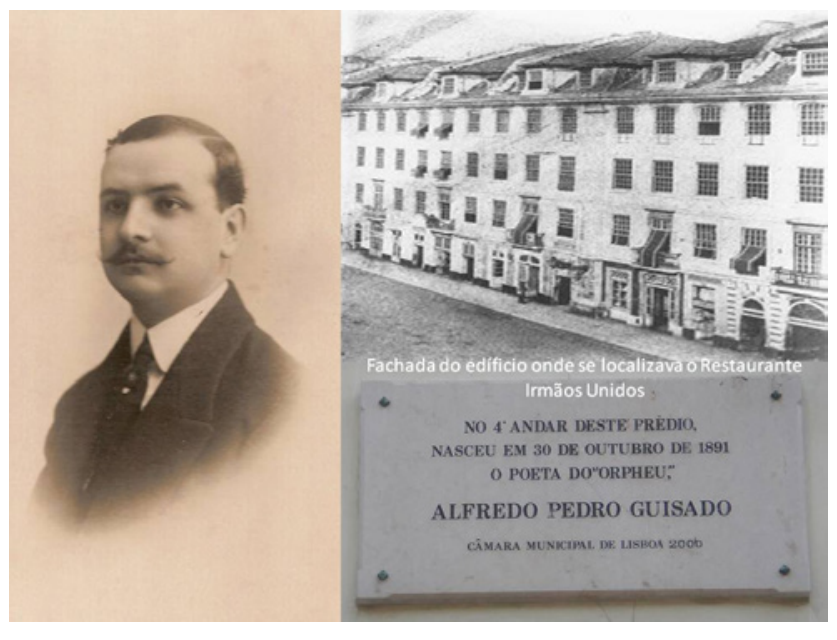

A família possuía uma boa condição económica e tinha negócios na área da restauranção, dos cinemas (cinema Royal), imobiliário (possuia andares e armazéns que alugava, por exemplo: Rua dos Douradores, Rua Praia da Vitória, Avenida Defensor de Chaves, etc.) e hotelaria (hotel Irmãos Unidos, que funcionava no mesmo edifício que o restaurante, e que fechou portas em 1930)

Alfredo era um jovem rebelde, irreverente (contra as ordens do pai, ia brincar para os campos de milho da sua quinta em Pias e estragava a plantação), e que era muitas vezes castigado, acabando por vezes por adormecer nos castigos!

Fez os seus estudos primários em casa com o Sr. Batista e estudou no Liceu do Carmo, onde provavelmente se cruzou com Mário Sá Carneiro, mais tarde seu companheiro de Orpheu.

A 6 de Janeiro 1912, edita o seu primeiro poema "Noites de Inverno", publicado no jornal El Tea (jornal semanal de Ponteareas, orgão defensor do agrarismo/regionalismo galego, e dirigido pelo republicano Amado Garra Castellanzuelo). No jornal $\mathrm{El} \mathrm{Tea}$, durante o período sob o qual este artigo incide, publicou quarenta e quatro textos.

A ligação à Galiza, a sua condição social, económica e política, permitiram que mantivesse relações de amizade com pessoas importantes do panorama político-social Galego, tais como: Alfonso Rodriguez Castelao (escritor, político, artista, e fundador do nacionalismo Galego), Dona Emilia Pardo Bazan (escritora aristocrata), Manuel Murguia (historiador Galego que impulsionou e criou a Real Academia Galega), Ramón Cabanillas (escritor Galego de pensamento nacionalista), Curros Enriquez (poeta e jornalista Galego que junto com Rosalia de Castro e Eduardo 
Pondal representava o ressurgimento da literatura galega), Enrique Peinador Lines (empresário e filantropo, fundador do balnário Mondariz, membro do partido Galeguista e Vice-Presidente da Sociedade de Agricultores de Pias - fundada por Guisado), Amado Garra Castellanzuelo (advogado e político, director do jornal El Tea e alcalde de Vigo no período de 1931-1932). A localização geográfica da paróquia de Pias também foi um factor importante nesses relacionamentos, pois em Pias situava-se a Quinta da família Peinador (onde se encontrava um museu dedicado à etnografia Galega), e a aldeia distancia-se a um quilómetro de Mondariz, que para além de ser local de termas de renome, era um ponto de encontro de intelectuais.

Ao longo do seu percurso literário, Alfredo Guisado assina textos como: Refalda Brila (resultado da reorganização do nome Alfredo Abril) em El Tea e no Semanário Lisboeta España y Portugal; Alfredo Abril em Riso da Vitória; Pedro de Meneses (resultado da conjugação do seu segundo nome com o apelido da avó materna) nos livros: Elogio da Paisagem (1915), As Treze Baladas das Mãos Frias (1916), Mais Alto (1917), Ânfora (1918), A Lenda do Rei Boneco (1920) e Xente d'aldea Poemário Galego em homenagem à paróquia de Pias (1921); Alfredo Pedro Guisado/ Alfredo Guisado nos livros: Rimas da Noite e da Tristeza (1913), Distância (1914), As Cinco Chagas de Cristo (1927), Tempo de Orfeu (1969), A Pastora e o Lobo e outras histórias (1974); Domingos Dias Santos - pseudónimo irónico utilizado na secção que tinha no jornal A República, intitulada Arcas Encoiradas; João da Lobeira pseudónimo utilizado numa secção do Jornal
A República, anti-regime Salazarista, PapelQuímico, de carácter irónico, da qual existe conhecimento que Salazar lia.

Em 1912, escreve o seu primeiro livro intitulado Rimas da Noite e da Tristeza. Os poemas deste livro foram escritos em Mondariz, Lisboa e A Coruña. O título do livro remete à algo tristonho, mas nesse mesmo ano faleceu a sua irmã mais velha, Palmira Guisado Abril. O título do livro é reflexo do estado de espírito do poeta, para além de que a palavra rima é consequência da reorganização das letras da palavra IRMÃ. O livro reflete o momento díficil que o poeta está a passar, grande parte dos cenários dos poemas são a paisagem campestre de Pias - local de brincadeira e de recordação da irmã. A morte da irmã é um acontecimento de tal forma marcante que em 1918 dedica-lhe o livro A Lenda do Rei Boneco e dá o nome de Palmira à sua filha. O seu primeiro livro encontra-se dedicado a: António Venâncio Guisado y Toucedo e a Benita Abril González (seus pais), no entanto tem poemas dedicados a: João Manuel Alfaia, António Ponce Leão, António Guilherme Guisado (seu irmão), Eugénio Alvarez Gonzalez (cunhado, marido da falecida irmã), Domingos Lago Gómez, Amado Garra Castellanzuelo, Hortensia Bermúdez, Pedro Midósi Bahuto, José Nunes Batista, Armando de Almeida, José Brandão (marido da sua prima direita), Álvaro Maia, João Nascimento, Álvaro Amadeu P. Maia, Maria José Ponce Leão, Rogélio Rivero, Diogo M. Duarte, Maria Zelinda Ponce Leão, Felipe Nogueira e o seu tio Guilherme Alfaya Fernandez (marido da sua tia, pelo lado materno, Pascoala Abril Gonzalez). 


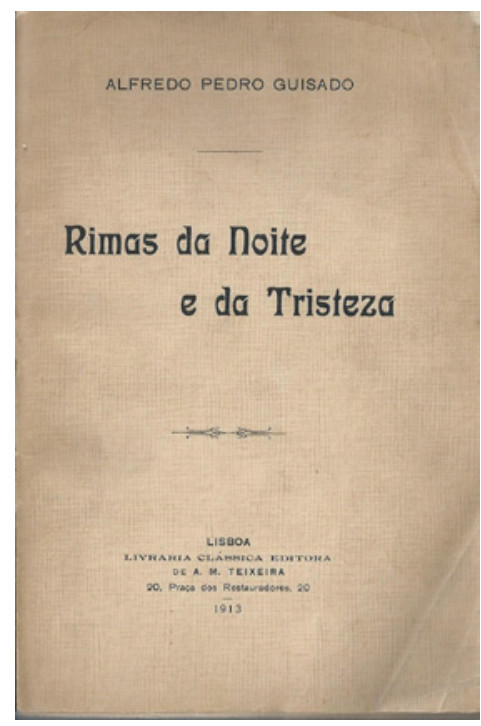

Alfredo Pedro Guisado pertencia ao Partido Republicano Português. O PRP foi legalmente criado, com consentimento do Rei D. Luís I, em Março de 1876, vínculado fortemente à maçonaria, e que, mais tarde, é dividido para dar lugar ao Partido Democrático de Afonso Costa, ao partido Evolucionista de António José de Almeida e à União Repúblicana de Brito Camacho. Provavelmente, foi no PRP que conheceu António Ferro, mais tarde seu companheiro de Orpheu. Muitas vezes surgem dúvidas se Alfredo Guisado era maçón, uma vez que estava associado ao PRP e à Sociedade Voz do Operário (Presidente), no entanto o próprio afirmava que apesar de ter muitos amigos maçón, não o era, e que não pertencia a nenhuma sociedade secreta.

Durante o período em análise, Guisado mantinha afincadas relações de amizade com ilustres figuras do enclave Galego de Lisboa, e desempenhou funções na Xuventud Galicia, na Associação Gallega de Socorros Mútuos em Lisboa, na União Agrária de los Agricultores del Partido judicial de Ponteareas em Lisboa e na Assembleia Geral da União Agrária da Galiza em Lisboa. É também nessa altura que Guisado se torna publicamente defensor do Agrarismo e do Nacionalismo Gallego. Funda a sociedade de Agricultores de Pias, tendo desempenhado várias funções ao longo da existência desta sociedade (1913-1935). Tornase presença assídua como colaborador do jornal El Tea, dirigido pelo seu amigo Amado Garra Castellanzuelo, que era um orgão defensor do agrarismo na Região do Condado (Mondariz, Ponteareas, Salvaterra do Miño e As Nieves), entre 1912-1913 publica cinquenta e quatro textos, sendo também um correspondente do jornal em Lisboa. Nesse jornal, para além de assinar com o seu nome e com o pseudónimo Refaldo Brila, assina também como: Xan Velliño (personagem de muitas histórias campestres associadas à sua aldeia).

No ano de 1914, lança o livro Distância, onde evidencia o neoromantismo. Este livro é dedicado aos seus companheiros António Ferro, Ponce Leão, Augusto Cunha, Fernando Pessoa e Mário de Sá Carneiro.

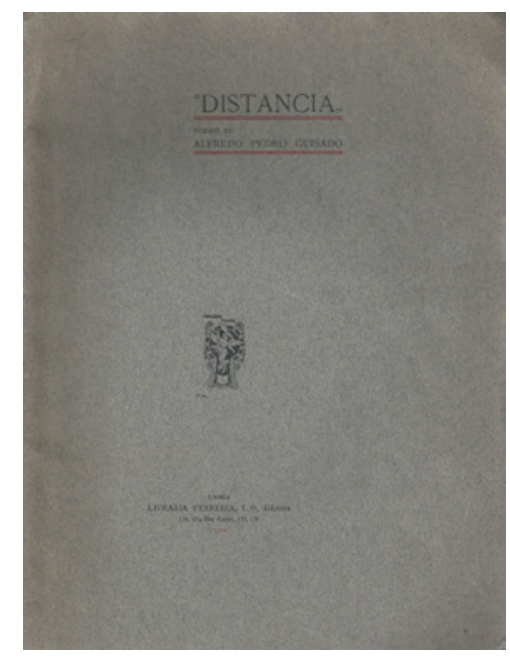


Guisado participa na revista editada em Coimbra, A Galera, em dois números: o primeiro a 20 de Dezembro de 1914, com o poema "Arabescos", e a segunda a 25 de
Fevereiro de 1915, com o poema "Só", num número dedicado a António Nobre, onde colaborou também Fernando Pessoa e Mário de Sá Carneiro.
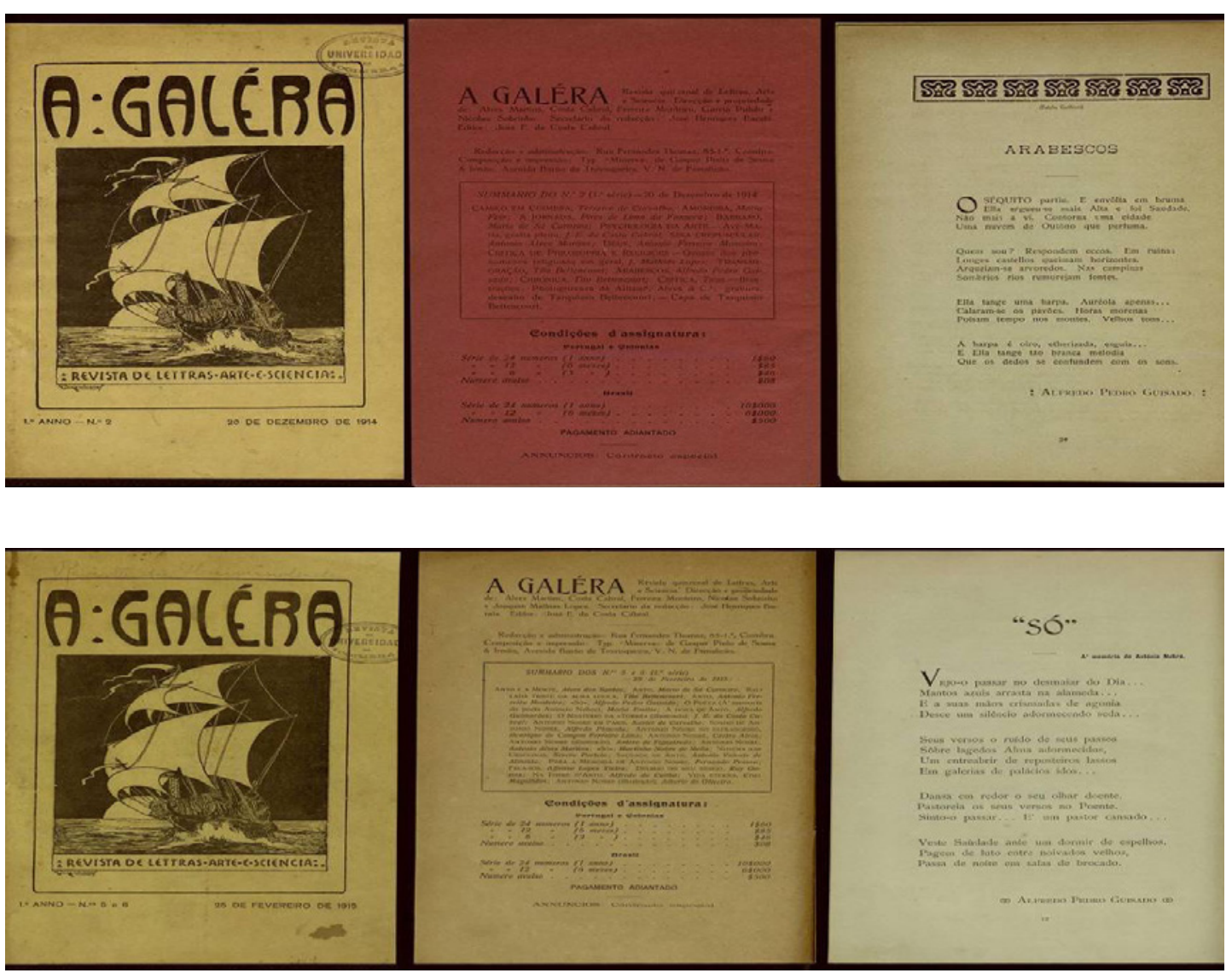

No ano de 1915, surge o mais famoso episódio do Modernismo Português, no restaurante Irmãos Unidos, o Orpheu! Dele faziam parte Fernando Pessoa, José Pacheco, Luis de Montalvor, Mário de Sá Carneiro, Alfredo Pedro Guisado, Armando Côrtes-Rodrigues, José de Almada Negreiros, Eduardo Guimaraens e Ronald de Carvalho. Numa entrevista, Guisado explica a razão de se reunirem nos Irmãos Unidos:
Como eu fazia parte daquela casa, que pertencia a meu pai e, onde eu estava, naquela altura empregado, pois nem sequer inscrito estava na Faculdade de Direito, o que aconteceu em Outubro desse ano (1915) e a revista saiu em Março-Abril, não me era possivel, por isso, afastar-me dali. Os meus companheiros de grupo, velhos e sinceros amigos todos eles, resolveram fazer naquele restaurante as suas reuniões 
para que eu pudesse assistir a todas elas. E nunca mais deixamos de ali reunir (1960, p.11).

A capa de Orpheu I, da autoria de José Pacheco, foi adaptada de uma outra imagem que Guisado trouxe de Ponteareas - Galiza, da casa do seu amigo Amado Garra. Guisado era visto como um financiador das edições do grupo (o pai de Alfredo Guisado financiou o Orpheu I com 120 contos) e Fernando Pessoa é incentivado por Mário de Sá-Carneiro a pedir-lhe dinheiro para Orpheu 2. Alfredo Guisado esteve no centro da origem dos heterónimos Alvaro de Campos e Alberto Caeiro:

O Orpheu foi logo para a typografia, (...) Começava, à parte o prefácio, com uns poemas de Sá Carneiro e fechava com a "Ode triunfal" do meu velho e inexistente amigo Álvaro de Campo. E, a propósito da "Ode Triunfal": para dar, mesmo para os próximos de nós, uma ideia da individualidade do Álvaro de Campos, lembrei ao Alfredo Guisado que fingisse ter recibido essa colaboração da Galiza; e assim se obteve papel em branco do Casino de Vigo, para onde passei a limpo duas composições. Lembro-me ainda do António Ferro e Augusto Cunha, então muito novo, e que frequentemente iam pelos Irmãos Unidos, lerem atentamente, sozinhos numa mesa ao fundo, essas composições inesperadas; assim como me lembro do Almada Negreiros, depois de ler com entusiasmo a "Ode Triunfal", me sacudir fortemente pelo braço, vista a minha falta de entusiasmo, e de me dizer quase indignado: "Isto não sera como v. Escreve, mas o que é a vida”. Senti que só a sua amizade me poupava à afirmação de que Álvaro de Campos valia muito mais do que eu (PESSOA, 1986, p.1325).

Relativamente a Alberto Caeiro, Fernando Pessoa descreve a partida pregada a António Ferro, com colaboração de Alfredo Guisado. Percebemos que Fernando Pessoa depositava confiança em Alfredo Pedro, tendo-lhe confiado o segredo dos seus heterónimos, ao ponto de ter de enganar o seu amigo António Ferro (que será o órfico que manterá uma relação mais duradoura e próxima com Guisado, no pós Orpheu I).

Como a única pessoa que podia suspeitar, ou, melhor, vir a suspeitar, a verdade do caso Caeiro era o Ferro, eu combinei com o Guisado que ele dissesse aqui, como que casualmente, em ocasião em que estivesse presente o Ferro, que tinha encontrado na Galiza "um tal Caeiro, que me foi apresentado como poeta, mas com quem não tive tempo de falar" ou uma coisa assim, vaga, neste género. O Guisado encontrou o Ferro acompanhado de um amigo caixeiro-viajante, aliás. E começou a falar no Caeiro como tendo-lhe sido apresentado, e tendo trocado duas palavras apenas com ele. "Se calhar é qualquer lepidótero" disse o Ferro. "Nunca ouvi falar nele..." E de repente, soa, inesperada, a voz do caixeiro viajante: "Eu já ouvi falar nesse poeta, e até me parece que já li algures uns versos dele." Hein? Para o caso de tirar todas as possíveis suspeitas ao Ferro não se podia exigir melhor. O Guisado ia ficando doente de riso reprimido, mas conseguiu continuar a ouvir. E não voltou ao assunto, visto o caixeiro-viajante ter feito tudo o que era necessário. (PESSOA, 1985, p.37-8) 


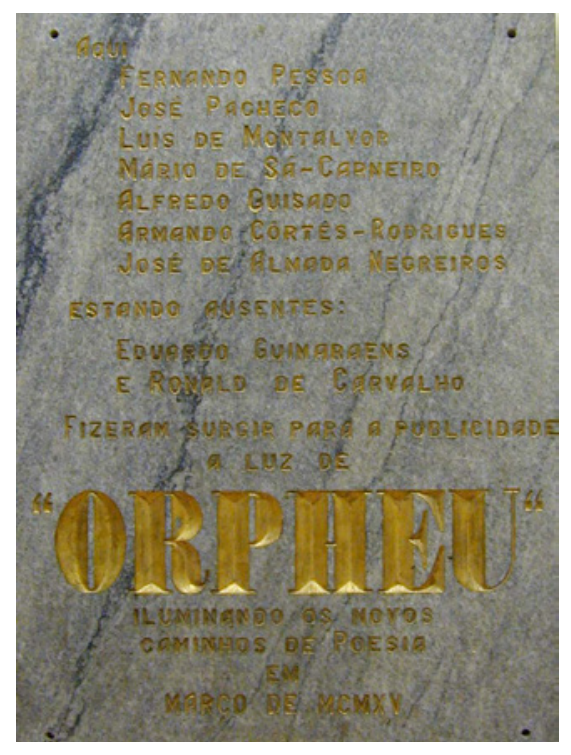

Em junho de 1915, é editado o segundo número da revista Orpheu, no qual Guisado afirma não ter participado pela razão de o poema se ter extraviado (República, 22 de Setembro de 1950). Nesse mesmo número, Armando Côrtes-Rodrigues, sob o pseudónimo de Violante de Cysneros, dedica um poema a Alfredo Guisado.

Em Junho de 1915, Alfredo Pedro Guisado e António Ferro anunciam o seu afastamento da revista e Mário de Sá-Carneiro embarca para Paris. O afastamento de Guisado da revista Orpheu deve-se maioritariamente a divergências políticas:
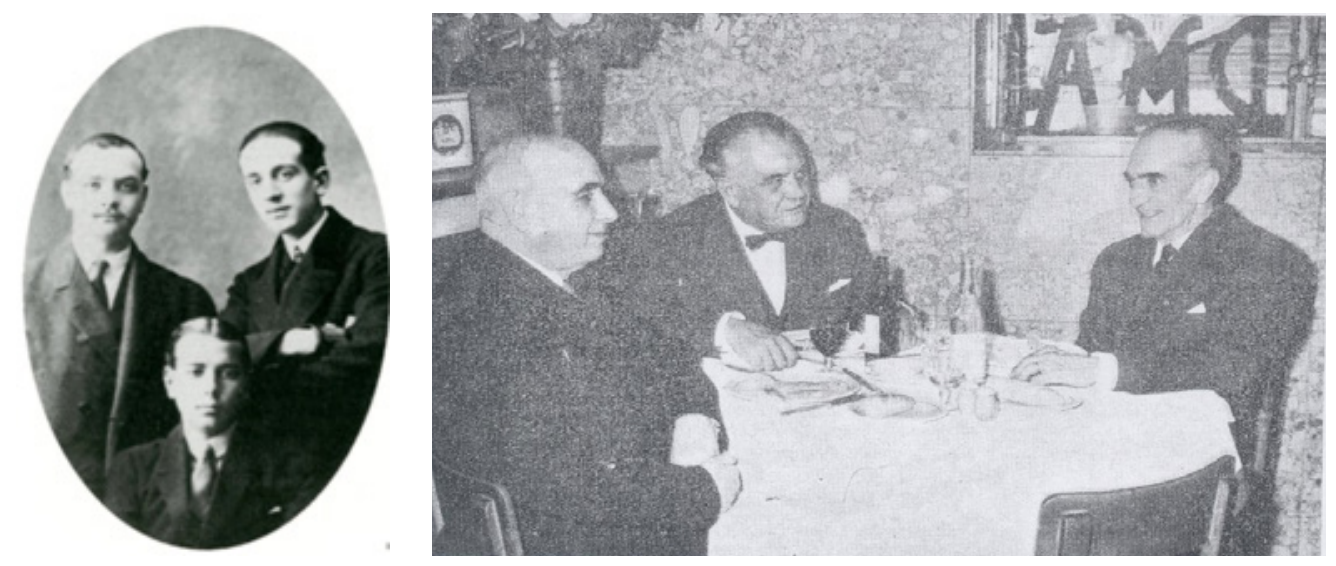

Em primeiro lugar, com Fernando Pessoa, devido à publicação feita pelo mesmo, juntamente com Raul Leal, ironizando episódios da vida do Republicano Afonso Costa, líder do partido onde Guisado militava. Esta publicação foi alvo de uma carta formal de desvinculação do grupo por parte de António Ferro e de Alfredo Guisado, publicada em O Mundo:
Sr. Director do Mundo - tendo chegado ao nosso conhecimento que um sr. Raul Leal, num manifesto, a titulo de colaborador do Orpheu e o sr. Álvaro de Campos (mas não é indicado o nome verdadeiro), colaborador também da mesma revista, numa carta dirigida à Capital, visaram a alta personalidade do Sr. Dr. Afonso Costa, por quem sentimos a maior admiração e cujo estado actual muito nos preocupa, vimos 
declarar que repudiamos qualquer solidariedade com esses senhores, o que o primeiro dos signatários já tinha feito em seguida à publicação do primeiro número do Orpheu, fazendo o segundo a afirmação que desde hoje deixa de ter qualquer responsabildade como editor da mesma revista. Agradecendo desde já a publicação desta carta, somos correligionários de sempre - Alfredo Pedro Guisado e António Ferro.

Em segundo lugar, a relação de Alfredo Guisado com Mário de Sá Carneiro não era a melhor. Em carta de Sá Carneiro a Fernando Pessoa, de 18 de Novembro de 1915, o remetente interroga ao destinatário:

(...) fale-me do Guisado. É criatura ainda tratável? Fez versos em Mondariz? Eu poder-lhe-ei escrever? Informe-me a este respeito. $\mathrm{Eu}$, por mim, gostava muito de lhe escrever, mas não sei o que ele tem contra mim, nem as intenções em que está! Informe-me você com toda a franqueza. Sabe bem que o Guisado será sempre para mim o admirável Poeta e excelente rapaz toldado de Burguesia (SÁ-CARNEIRO, 2003, p. 118).

Por último, a relação com José de Almada Negreiros também era relativamente tensa, como percebemos, para além da critica feita no "Manifesto Anti-Dantas", através da expressão: "os menus do Alfredo Guisado", pela seguinte afirmação:

Cortei relações pessoais com dois companheiros do Orpheu, primeiro por ousarem manifestar as suas opiniões politicas, o que era inadmissivel entre nós (...) mas sobretudo por estes mesmos manifestarem indacredivelmente as suas repulsas mentais e fisicas por Raul Leal. De resto, estes dois companheiros eram os que menos eram de Orpheu. Parece-me (NEGREIROS, 2014, p.104).

Mas apesar destas brigas, Alfredo Guisado mantinha uma boa relação com o grupo, continuando a relacionar-se com o mesmo.

Em Outubro de 1915, Alfredo Guisado inscreve-se na Faculdade de Direito de Lisboa, onde se irá formar no ano de 1921. O poeta exerceu Direito de uma forma esporádica.

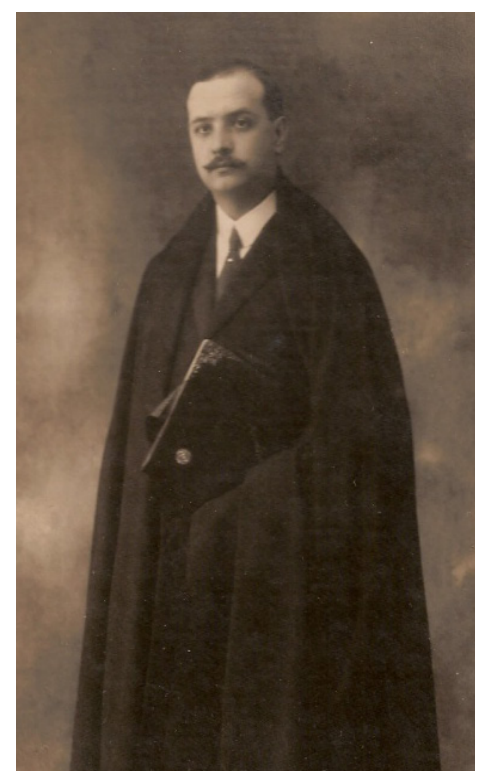

No ano de 1915, Guisado edita mais um livro, Elogio da Paisagem, que teve a particularidade de ter duas capas, isto é, uma tiragem foi feita com uma capa assinada como Alfredo Pedro Guisado, e outra como Pedro de Meneses. Este livro foi alvo de várias recensões críticas. Na revista Exílio, Fernando 
Pessoa comenta o livro Elogio da Paisagem, escrevendo:

A breve e magistral colheita de sonetos, que o sr. Pedro de Menezes fez para o seu publico, marca bem a individualidade definida, que elle tem a dentro do Sensacionismo. A exhuberancia abstracto-concreta das imagens, a riqueza de sugestão na associação d'ellas, a profunda intuição metaphysica que socleia tanto os versos culminantes dos sonetos d'esta plaquette, como, basta vezes, a direcção animica de certos sonetos integralmente - tantas são algumas da razões que um espirito esclarecido e europeu encontra para admirar e amar o Elogio da Paisagem. [...] Convém não omitir que o sr. Pedro de Menezes junta ás suas grandes qualidades dois defeitos, que, não chegando a empanal-as, certo é que não deixam que ellas tenham o relevo a que teem jus. O primeiro defeito é uma certa deficiencia-por vezes accentuadamente notavel - de musicalidade, de suggestão puramente syllabica, se seducção rhythmica pura[...] O seu outro defeito é menos frequente e, onde está, é, em geral, menos sensivel. É que por vezes o poeta esquece as leis, não só exotericas, mas esotericas também, da associação de ideas desconnexas, e juxtapõe imagens que, sendo quasi sempre, cada uma d'ellas bella, não se fundem em belleza, não se synthetisam suggestivamente no espirito (1982, p.47).

Ao mesmo livro, em Alma Nova, A. Bustorff, no ano de 1915, manifesta-se:

já nem mesmo aparece nas montras das livrarias - de velho e esquecido que está para o burguesismo triunfante - o Elogio da Paisagem de Pedro de Menezes. Edição agradável, guardando catorze sonetos de onde se destacam algumas jóias literarias que bem traduzem a alma de puro requinte artistico de quem as sonhou. Arte moderna, arte de dificil intuição. - arte quasi estravagante. Por vezes mimos de ritmo, de ideia e de delicadeza, como a canção das fiandeiras e ainda a Romaria dos Echos; mas sobre estes predominam os que, por uma excessiva sintese, dificultam a sua penetração. Porque não regressará Pedro de Menezes ao cultivo de formas poéticas claras, mas unanimemente louvaveis, onde já tem maravilhas da força da Lenda do Mar, da Lenda dos Sinos ou das Lareiras?...

António Ferro, no Exílio, elogia o livro Elogio da Paisagem, escrevendo:

A paisagem deve sentir-se lisongeada... Pedro de Menezes fez o seu elogio... Os versos do poeta não lhe disseram apenas a beleza... Deram-lhe mais Beleza... Brilhantes que num gesto magnanimo Ele atirou ao seu regaço... Porque a Paisagem não é tão bela... Pedro de Meneses não deveria ter dito Elogio, mas sonho da Paisagem... Cada verso deste poeta lê-se como quem percorre uma alameda, onde a Ideia passeie como uma princesa scismadora... Ao meio um lago onde de quando em quando ela mergulha as mãos... Pedro de Meneses, como todo o Português, descende do Gama, descubriu no seu espirito, um reino mais longinquo do que a India, o reino do Preste-Deus!... (1982, p.45). 
Em Dezembro de 1915, em A Águia, Elogio da Paisagem é visto da seguinte forma:

O soneto, felizmente para quem o usa, presta-se a tudo: ás pequenas esculturas imortaes encerrando em quatorze linhas a tragedia duma vida ou dum povo, e aos histors manequins de certos enxambladores do verso para quem o valor se mede pela originalidade no escandalo. O sr. Menezes, a quem desejaríamos melhor sorte, deixou-se levar por esta ultima feição. Fazemos votos pelo seu completo restabelecimento."

Em Abril de 1916, juntamente com Augusto de Santa-Rita, António Ferro e Armando Côrtes-Rodrigues, funda a revista Exílio com artigos nas áreas de literatura, música, ciência, filologia e crítica. Nesta revista colaboram também Teófilo Braga e António Sardinha.

\section{REFERÊNCIAS}

AUTORES: A história do 'Orpheu'. Confidências de Alfredo Guisado. In Autores, outono/1960, pp. 10-11.

CAMELO, José António. Do galeguismo de Alfredo Pedro Guisado ou Pedro de Menezes. In Agália, 2, 1985, pp. 191-196.

EXÍlIO, edição fac-similada. Org. Teresa Almeida. Lisboa: Contexto, 1982.

GUISADO, Alfredo e FERRO, António (1915): "Os do «Orfeu»" In: O Mundo, 7/07/1915.

JÚDICE, Nuno. A era do Orpheu, Lisboa, Teorema, 1986.

JUSTO, Carlos Pazos. Trajectória de Alfredo Guisado e a sua relação com a Galiza (19101921), Santiago de Compostela, Laiovento, 2010.
LOURENÇO, António Apolinário. Introdução In: Alfredo Guisado: Tempo de Orfeu, Coimbra, Angelus Novus, 2003. pp. XI-XLIX.

NEGREIROS, Almada. Orpheu: 1915-1965. In: Orpheu 1915-2015 - Textos doutrinários e fortuna crítica (antologia). Org., prefácio e notas de Carlos Felipe Moisés. Campinas: Editora da Unicamp, 2014. pp. 95-125.

PESSOA, Fernando. Cartas de Fernando Pessoa a Armando Côrtes-Rodrigues. Introdução de Joel Serrão. Lisboa: Livros Horizonte, 1985.

Obra poética e em prosa. Org. António Quadros. Porto: Lello \& Irmão Editores, 1986, vol. II.

SÁ-CARNEIRO, Mário de. Correspondência com Fernando Pessoa. Ed. Teresa Sobral Cunha. Lisboa: Relógio D’Água, 2003 v.2.

Recebido para publicação em 18 nov. 2016. Aceito para publicação em 23 dez 2016. 